\title{
6 Reasons of the Failure of Reforms in Companies
}

\section{Agayev Fahri*}

Department of Economics and Business Management, University of Marmara, Egitim Mahallesi, 34722, Istanbul, Turkey

*Corresponding author: Agayev Fahri, Department of Economics and Business Management, University of Marmara, Egitim Mahallesi, 34722, Istanbul, Turkey, Tel: +902164140545; E-mail: fahriagayev@yandex.ru

Rec date: May 10, 2017; Acc date: September 22, 2017; Pub date: September 29, 2017

Copyright: (c) 2017 Fahri A. This is an open-access article distributed under the terms of the Creative Commons Attribution License, which permits unrestricted use, distribution, and reproduction in any medium, provided the original author and source are credited.

\section{Introduction}

\section{Reforming leaders act to avoid failure}

Over more than 15 years of activity as a manager, I implemented changes, reforms, modern management systems in different companies and observed how my colleagues solved these problems. I often witnessed that changes started at high speed, skidded or rolled down to the starting point after the start. Summarizing these observations and information on the implementation of reforms in big Western companies, I identify six main reasons why reforms are not successful or brought to the end [1].

\section{Poor communication, lack of information}

Top management is well aware of the importance of vision, strategic goals, operational plans, values, adhering to which the company will move towards its goals. But do middle-level managers and ordinary employees know about this? One of the main tasks of management at this stage is the effective dissemination of full and clear information about the changes among the staff [2]. If people are not given explanations, they have to interpret the events themselves. And often in such situations, the opponents of reform come to the forefront. All kinds of provocateurs and informal leaders lead the turmoil, spreading their understanding of changes, frightening dismissals and depressions, interpreting fuzzy messages from the leadership in their own way.

What happens when the information is not delivered in full form to the middle-level management and ordinary personnel? Right, resistance to changes begins.

Jack Welch who is famous for his reforms in the "General Electric" corporation, writes about the importance of communications in his book "Winner": "The head has to constantly, until exhausted, convince the subordinates in the concept of development. And we need to make everyone understand the concept. One of the most common problems is that managers bring the concept of development only to the attention of their closest colleagues, while its meaning remains unclear for ordinary employees. Remember all those cases when, during a visit to a department store with a high class of service, you encounter a rude or overly hasty seller, or when talking to a call center operator takes too much time, despite the fact that the mobile phone company promised a fast and convenient service for you. Somehow it turned out that these people were not acquainted with the tasks set by their leaders. Perhaps the reason is that they were told about it not too loudly and not too often."

\section{Importance in Understanding}

- The introduction of changes is primarily an information war. Supporters of reforms should correctly, accurately and effectively convey information to people, while not forgetting that those thinking in the style of "and so everything was normal" will conduct their explanatory work.

- No change can be successful without informing and communicating with people.

- All changes and all values will be implemented by those who work with clients. These are ordinary personnel and middle-level management, not the top management that develops plans. It is necessary that the staff also feels the essence and importance of the changes.

- Employees have the right to get information about the planned reforms. The responsibility of the leadership is to convey it in a clear and precise way.

- To communicate the correct information, you must use all possible means of communication. In one of the organizations I created an internal development academy specially for this purpose, explanatory works were conducted through the organization of seminars, trainings, brainstorming sessions involving middle and linear management.

- It is important to involve people in the discussion of real problems. The feeling of involvement is a very strong motivator, as people understand that their opinions and thoughts are given importance.

- It is important not to leave any question or doubt unanswered or clarified by personnel and middle management.

\section{Managing Importance}

- Do not try to look cool using incomprehensible terms. Middle management over the age of 40 cannot understand abstruse words like KPI, Lean Production, etc. Communicate with employees in a language they understand. Before each meeting with the staff, ask yourself the question: what do I want to do: to stun people with my knowledge or to explain my ideas to them.

\section{Inability to Stand Against Resistance}

In the case of expected, but ambiguous changes in a company, the staff moves from a familiar and comfortable state to an unaccustomed one. The employees have a feeling of discomfort and on this basis, resistance to changes grows. It is at this point that people begin to listen to informal leaders and local "stars" who do not want reforms [3].

Here are some of the reasons for sabotaging the changes that I have witnessed in my practice: 
- Continued success, generating inertia in the company.

- Absence of an objective for regular changes and improvement in the corporate culture.

- Unhealthy aura, when anyone who is "for" changes is called a traitor and is badgered.

- Arrogance: we led the company to today's success, and only we know how to conduct business further.

- Fear of losing job or authority/ power as a result of reforms.

- Fear of punishment for mistakes in the new system.

- Understanding your own unpreparedness for new requirements, fear of losing your job due to the lack of necessary knowledge and skills.

- Fear of not adapting into the new system.

In principle, any changes cause anxiety and stress among people. Therefore, helping them to understand the essence of what is happening, you can ease the feeling of anxiety, reduce the craving for resistance and give the opportunity to not only listen but also hear.

Can resistance affect the course of changes? Yes, it can. Moreover, it can not just affect the speed or direction of the changes, but kill them off. In every company, you can meet people who have experienced many reforms and who say: "All we have seen your reforms! Look how many people prior to you tried to remake the system, and they failed. The leadership will still cancel everything. "

\section{Importance of Envisage}

- To understand that everything begins in the mind of people - both doubts and confidence.

- Changes and reforms are not carried out only administratively.

- It is necessary to understand people's fears, anxiety and doubts.

- It is important to identify positive and negative-minded informal leaders.

- The basic skill required to implement changes is communication. It is necessary to patiently explain people their position, to strive for understanding their real fears.

- After determining the main reasons for resistance, a plan of action should be drawn up and acted upon.

- Not enough knowledge? To hold seminars, trainings, personal or group meetings and consultations.

- Do people have any doubts about the appropriateness of the changes? To meet with them, to clarify, to share your experience.

- Are people afraid of the intensity and speed of changes? To give them information about the situation on the market, to explain why it is dangerous to delay. To ask the staff for guidance questions so that they themselves come to the importance of reform.

- Are people afraid of making mistakes? Create an atmosphere of trust, tell us about your mistakes and do not punish anyone for mistakes.

- It is important to understand the hidden thoughts of people that no one will ever voice, and give answers to them.

\section{Inability to Neutralize Saboteurs}

In order to properly distribute one's energy in the fight against opponents of reforms, it is necessary to know in advance which groups of people can resist, what power they have and the degree of influence they have on the team. In my experience, there are two types of influential opponents of reforms in companies:

Senior management or influential coalitions/groupings. Basically, these are groups, united according to the local principle or common interests. It is most difficult to agree with these groups, because they already have their own vision, their goals and plans, and anyone who does not fit into their accustomed world is an enemy. Possessing formal power, they can cause quite a lot of headaches [4]. For them, the presence of a reformer in an organization is a potential danger, and for this reason the achievement of the status quo is simply impossible at an ideological level. The simplest example. The company has a top manager or a group of people who are corrupt and have their own financial interests. And for this reason they will sabotage the creation of transparent financial statements, which will reduce their illegal incomes.

\section{Informal Leaders}

Who is the informal leader of the organization? It can be a person without any managerial positions, with a complete lack of formal power, but having real power and which can have a serious impact on people's opinions on almost all issues. Having made a career from scratch and having gone through all the steps of the career ladder, I saw what powerful influence some uncle Vasily might have. What forms of influence do informal leaders have in companies?

- Expressing doubts about the appropriateness of the changes and their favorable outcome.

- Strong negative feedback about those who join the reformers. At one point everyone gets a message: who is with them, he is against us.

- Hiding important information.

- Superficial execution of new processes.

- A demonstrative passive or disparaging attitude towards the management's words.

- Open or hidden sabotage.

- Mobbing, harassing supporters of reforms of their rank or their social isolation.

There is an important layer in each of these groups: the old guard. These are the ones who actually built the company from scratch, whose qualities and skills were extremely important in the previous stages [5]. With the old guard, though difficult, you can agree, because they are mostly honest hard workers, who gave the company their best years. Each member of the old guard has a lot of stories about how they did not sleep a day, shipped carriages, carried on the production. They must be respected. They must be understood. You can and need to negotiate with them. One of the main fears of the representatives of the old guard which they will never admit is the fear that they may not fit into the new management system due to the lack of modern knowledge or ignorance of new technology. But the old guard will conspire with the first group and informal leaders only if they feel danger for themselves and do not understand the purpose of the reforms. 
Page 3 of 4

At the same time, both major groups of saboteurs will try to use veterans in the information war. People from the first group, in view of their positions, will officially support the changes, but at the same time warm up the fears of the old guard in order to influence the mentality of the staff, to reduce the speed and efficiency of innovations. What do I advise in such cases? To conduct serious educational work with the old guard, to involve veterans in discussions, meetings, to bring their successes as a positive example for employees. At the same time, with the help of the old guard, pressure should be put on informal leaders [6].

\section{Inconsistency Of Words, Statements And Deeds}

Nothing harms transformations like actions of a leader that disagree with his/her words. People immediately get an important message: you can beautifully talk, demand, and do not act or act superficially. Personally, I witnessed a situation in a large company, in which a dress code was introduced: new rules were written out, their need was explained, management held meetings with top and middle management. Everyone listened attentively, asked questions: the staff was involved. On the appointed day, everyone was dressed in a dress code, in suits and ties. The general aura in the company immediately changed, all became more focused, serious, the style of communication imperceptibly changed [7]. Of course, there were discontent employees, but their voice was not audible. However, a week later the leader appeared in the office without a tie. In a couple of days - without a suit. A week later everyone else relaxed the tie and a couple of employees did not wear a tie at all. And after a while everyone returned to the old form of clothing.

- Do not forget the priceless words of Abraham Lincoln: "Your actions are so loud that I do not hear your words."

\section{Unpreparedness for long-term work}

Whatever changes we talk about - technological, in business processes, in the rules of work - in fact, we are talking about making changes in people's habits. And it's not just about making changes, but about replacing old habits that have been formed over years with the new ones. Such a process takes time: one must know people, leadership, middle management, identify formal and informal leaders, conservatives, opponents, dissenters, understand and feel people's fears, form a vision and values and bring them to people, change habits, fix them, fight resistance [8].

I often paid attention to one common feature among the reformers: having achieved their first success, they relax and get removed into the comfort zone themselves. Or they forget that the fears and doubts of subordinates remain, processes and habits are not fixed, some remained dissatisfied and did not receive what they demanded. As a result, after the first period of a leap forward, the changes start to drift. From this moment the recession begins. Thus, victory in the first battle turns into a defeat in the war.

\section{Steps to follow}

- Remember that change is a long way.

- Understand that change is not a strategy, not a set of techniques or tools, but work with people who will implement this strategy by applying new techniques and tools.
- Pay attention to the fact that it is most difficult to change the consciousness of people. A person (especially over 50), who is used to acting according to one old procedure, has difficulties in changing for a day or a week.

\section{Lack of Persistence and Perseverance}

Persistence in conducting reforms means not only the ability to take blows, but the willingness to explain day by day their goals and vision to people of different ages, sex, with different views on life, but united by the thought of the danger of change. It is important not to be afraid to argue with them, find the strength to discuss the situation again and again, leading each group of opponents their arguments and arguments. In response, the dissatisfied and dissenters will continue to show discontent, attack openly or slyly, arrange provocations. Nevertheless, the reformer should not retreat [9].

- We need to focus on the main areas of reform, since time and energy are very limited, and they need to be spent effectively.

- It is important to avoid open confrontation. All sorts of disassembly will take away energy and strength, lead away from solving the most important tasks. And three months later the same people who involved you in them will ask the main question: what has been done?

- It is necessary to distinguish the most important of all the variety of tasks, correctly formulate goals and boldly cut off secondary ones.

- It is important not to lose heart, every day doing one small step in each of the selected priority areas.

- It is important to understand that the introduction of changes is also a struggle of patience. The more patient and persistent one will win.

\section{All the Links in the Chain are Important}

The introduction of changes in the company is a complex work that must be conducted on all fronts and directions. I advise to treat this activity as a chain, each link of which should be strong enough. The weakness of one of the links will lead to a common failure.

Imagine a situation where changes are planned in the company. The leadership has a vision, plans, strong communication, the actions of the leaders completely coincide with their words, they are prepared for long-term work and try to consolidate the changes in the corporate culture. But only weak communication can destroy all efforts. The same rule applies to each of the above items [10].

No matter how beautiful words, mottos, slogans, terms, goals and intentions (such as the introduction of modern management systems, the introduction of an efficiency assessment system) the leadership has, one must remember one single rule: everything is done by people. For this reason, the cornerstone of all changes should be competent and effective work with people.

\section{References}

1. Coffee JC (2004) Gatekeeper failure and reform: The challenge of fashioning relevant reforms. BUL Rev 84: 1-301.

2. Ahluwalia MS (2002) Economic reforms in India since 1991: Has gradualism worked?. The Journal of Economic Perspectives 16: 67-88. 
3. Richardson CJ (2006) Learning from failure: Property rights, land reforms, and the hidden architecture of capitalism. American Enterprise Institute for Public Policy Research.

4. Morriss AP, Yandle B, Meiners RE (2001) The Failure of EPA's Water Quality Reforms: From Environment-Enhancing Competition to Uniformity and Polluter Profits. UCLA J. Envtl. L. \& Policy 20: 1-25.

5. Höreth M (2008) A Successful Failure? The Contested Implications of Germany's Federal Reforms. German Politics 17: 408-423.

6. Kiguel M (2002) Structural reforms in Argentina: Success or failure?. Comparative Economic Studies 44: 83-102.

7. Nepal R, Jamasb $T$ (2015) Caught between theory and practice: Government, market, and regulatory failure in electricity sector reforms. Economic Analysis and Policy 46: 16-24.
8. Elman BA (2004) Naval Warfare and the Refraction of China's SelfStrengthening Reforms into Scientific and Technological Failure, 1865-1895. Modern Asian Studies. 38: 283-326.

9. Xue Y, Liang H, Boulton WR, Snyder CA (2005) ERP implementation failures in China: Case studies with implications for ERP vendors. International Journal of Production Economics 97: 279-295.

10. Rose AS, Palifka BJ (2016) Corruption and government: Causes, consequences, and reform. Cambridge university press. 